\title{
SCREENING OF RHAMNOLIPIDS FROM Pseudomonas spp. AND EVALUATION OF ITS ANTIMICROBIAL AND ANTIOXIDANT POTENTIAL
}

\author{
Ayana Rose R. Mendoza* ${ }^{1}$, Jenny Marie R. Patalinghug ${ }^{1}$, Grace O. Canonigo ${ }^{2}$, Jonie C. Yee ${ }^{3}$
}

Address (es): Ms. Ayana Rose R. Mendoza,

${ }^{1}$ Graduate School of Arts and Sciences, Department of Biology, University of San Carlos, Cebu City, Philippines 6000.

${ }^{2}$ Department of Biology, University of San Carlos, Cebu City, Philippines 6000.

${ }^{3}$ Applied Microbiology Laboratory, Department of Biology, University of San Carlos, Cebu City, Philippines 6000.

*Corresponding author: yani.10696@gmail.com

\section{ABSTRACT}

Biosurfactants are amphipathic compounds that are useful in industries and are also used in bioremediation. Rhamnolipids (RL) are biosurfactant mostly produced by the genus Pseudomonas. This study screened 6 strains of Pseudomonas isolated from underwater cave sediments to determine if they were capable of producing rhamnolipids. The biosurfactant production of potential strains was screened by Parafilm-M Test, Oil spreading technique, Microplate assay, Emulsification Index, CTAB Agar plate method, Anthrone test, and Thin Layered Chromatography. The study showed that only 3 strains had the potential to produce rhamnolipids, these were Pseudomonas poae, Pseudomonas fluorescens and Pseudomonas libanensis. The antimicrobial activity of the crude rhamnolipid extracts was tested against two Gram-negative bacteria (Escherichia coli, Serratia marcescens) and two Gram-positive bacteria (Bacillus cereus, Staphylococcus aureus) by the conventional minimum inhibitory concentration (MIC). The antioxidant activity of the crude rhamnolipid extracts was determined through DPPH free radical scavenging assay. All rhamnolipid extracts had a positive correlation between increasing concentrations and the zone of inhibition against test microorganisms. Rhamnolipids from $P$. libanensis had the lowest MIC among the other extracts, indicating its potency against the test bacteria. The rhamnolipid extracts were effective at inhibiting the test bacteria compared to the positive control, Nitrofurantoin. The antioxidant activity of the crude rhamnolipid extracts was determined through DPPH. Crude rhamnolipid extracts exhibited antioxidant activity but not as great as that of ascorbic acid.

Keywords: Rhamnolipids; Biosurfactant; Pseudomonas; Antimicrobial; Antioxidant

\section{INTRODUCTION}

Marine and freshwater ecosystems are home to a diverse array of organisms due to the fluctuating environmental parameters (Molles, 2010). Biodiversity in these environments are high, the organisms have various adaptations in their physiology for them to survive. One adaptation is the production of metabolites (Bhatnagar and Kim, 2010). These are substances that are not required for growth by the organism but may be used for protection. These can be extracted from organisms like plants, fungi, algae, and microorganisms. The substances, when processed, can have various uses such as antimicrobial medicine, biosurfactants, and more. Pseudomonas is a genus of Gram-negative, aerobic, and flagellated Proteobacteria (Bauman, 2006). Species of this genus can be found in terrestrial, freshwater, and marine habitats. The terrestrial Pseudomonas aeruginosa is known to produce bioactive substances, other species of Pseudomonas are not well studied in terms of bioactive substances. The genus has been known to produce about 610 antibacterial substances (Isnansetyo and Kamei, 2009) and has the potential to produce Rhamnolipids, a type of biosurfactant (Cortes-Sanchez et al., 2013).

The emerging problems of multi-drug resistant bacteria have become a global problem (Cardozo et al., 2013) and the discovery of novel antimicrobials coming from new sources like freshwater Pseudomonas might help lessen the problem. Oil pollution in water systems is also an arising issue that threatens the aquatic and marine ecosystems (Wiedenhoft, 2017). Biosurfactants are amphipathic compounds found in the bodies of organisms. They are usually in the form of glycolipids. The extraction of biosurfactants from abundant and sustainable sources like bacteria is becoming an interest in the industry due to the wide array of functions it can offer. Biosurfactants can help disperse spilled oil more efficiently than commercial surfactants and has lesser toxicity (Cortes-Sanchez et al., 2013) so this can help address the pollution of aquatic and marine ecosystems in a more sustainable way via bioremediation. Pseudomonas aeruginosa is known to produce biosurfactants in the form of Rhamnolipids. Aside from being used as oil dispersant, rhamnolipids have also been discovered to have antimicrobial properties against pathogens like Serratia marcescens (Haba et al., 2003) contributing to the issue on the need for novel antimicrobial sources. Rhamnolipids can also inhibit the biofilm formation of other microorganisms so they can be spread onto substrates that need protection from microbial colonization (Singh and Cameotra, 2004). A study on the produced biosurfactants and antimicrobial activity of other Pseudomonas species will be a timely and relevant solution to address the issues we face today. This study is important because it explored the other biosurfactant and antimicrobial activity that the metabolites of the genus Pseudomonas can produce. There have been studies showing the potential of biosurfactants to act as antioxidants so they can delay the spoiling of food while being less toxic than BHA (butylatedhydroxyanisole) and BHT (butylatedhydroxytoluene). However, none of the published studies investigated the antioxidant activity of rhamnolipids which is important because it helps the scientific community and industries in the innovation of more sustainable ways to preserve food that does not threat the health of the people.

This study aimed to screen for the bioactivity of rhamnolipid producing Pseudomonas spp. isolates from the underwater cave of Casili, Balamban, Cebu, Philippines sediments with the following specific objectives in mind to: qualitatively screen for biosurfactant production of the isolated Pseudomonas strains through (a) Parafilm M test, (b) oil spreading assay, (c) microplate assay, (d) emulsification capacity assay, (e) CTAB agar plates, (f) anthrone test and (g) thin layered chromatography; to measure the MIC of the crude rhamnolipid extract on two Gram-positive bacteria (Bacillus cereus and Staphylococcus aureus) and two Gram-negative bacteria (Escherichia coli and Serratia marcescens); to compare the zone of inhibitions of the crude extract to those of commercial antibiotics (Ciprofloxacin and Nitrofurantoin), and to determine if crude rhamnolipid extracts exhibit antioxidant activity through DPPH free radical scavenging method.

\section{MATERIAL AND METHODS}

\section{Bacterial strains}

The Pseudomonas species that were acquired from the Microbiology Laboratory of the University of San Carlos which were isolated from aquatic sediment. The strains were stored and maintained in the laboratory using PYG agar prior to the screening of biosurfactant: (1) Pseudomonas poae, (2) Pseudomonas reactans, (3) Pseudomonas parafulva, (4) Pseudomonas fluorescens, (5) Pseudomonas libanensis and (6) Pseudomonas sp. These isolated Pseudomonas species were used and designated as Strains 1 to 6 throughout the experiment.

\section{Rhamnolipid Production}

Each Pseudomonas strain was cultured in a 250-mL shake flask for the production of rhamnolipid. The method of Wang et al. (2007) was followed where the strains were first grown in nutrient broth for 24 hours and shook at 200 $\mathrm{rpm}$ with a temperature of $30^{\circ} \mathrm{C}$ before being introduced to the rhamnolipid media and incubated at the same conditions for 7 days. Then $5.0 \mathrm{~mL}$ of nutrient broth was inoculated in $50 \mathrm{~mL}$ of rhamnolipid production media, following a 1:10 ratio, similar to that of Wang et al. (2007). The rhamnolipid media utilized in this study follows that of Thanomsub et al. (2007). After incubation, each 
culture was filtered by using a $0.2 \mu \mathrm{m}$ Whatman membrane filter to obtain cell free broths for biosurfactant screening.

\section{Screening for biosurfactant}

\section{Parafilm M Test}

Fifty $\mu \mathrm{L}$ was taken from each of the 6 cell-free broths and was dropped in the surface of hydrophobic side of the parafilm M. After 1 minute, the diameter of the drop was measured using a ruler. A negative control which was water was also set. A drop which had larger diameter than that of the distilled water was considered positive for biosurfactant.

\section{Oil Spreading Assay}

Five hundred $\mu \mathrm{L}$ of colored oil was added to the surface of $40 \mathrm{~mL}$ of water in a petri dish to form a thin oil layer. Then $250 \mu \mathrm{L}$ of cell free broth for each strain was gently placed on the center of the oil layer and after 10 seconds, the diameter of any formed clearing zone was measured with a ruler. Three trials for each strain were observed.

\section{Microplate Assay}

A $100 \mu \mathrm{L}$ cell-free broth of each strain was taken and put into separate microwells of a 96-microwell plate. The plate was viewed using a backing sheet of paper with grid lines. The presence of biosurfactant was indicated by optical distortion of the grid lines.

\section{Emulsification Capacity Assay}

To calculate the emulsification index, $2 \mathrm{~mL}$ of kerosene was added to $2 \mathrm{~mL}$ of the cell free broth in the test tube and was vortexed at high speed for 1 minute. After 24 hours, the height of the stable emulsion layer was measured. The percentage of the emulsification index was calculated as the ratio of the height of the emulsion layer and the total height of the liquid.

\section{CTAB Agar Plates}

The Pseudomonas strains were cultivated in a light blue mineral salts agar plates that contained the cationic surfactant cetyltrimethylammonium bromide (CTAB) and the basic dye methylene blue. After incubation, plates were placed at $4{ }^{\circ} \mathrm{C}$ for $24 \mathrm{hrs}$. Positive reactions were caused to darken significantly and to make visible weak positive reactions that were not apparent upon initial inspection.

\section{Rhamnolipid Recovery}

Rhamnolipids in the cell free broths of the strains was made less soluble in the aqueous phase by acidifying with $5 \% \mathrm{HCl}$ to $\mathrm{pH} 3.0$ which neutralized the negative charges on the rhamnolipids and precipitate. The precipitated rhamnolipids were recovered by solvent extraction using ethyl acetate.

\section{Anthrone Test}

Fifty $\mu \mathrm{L}$ of each ethyl acetate layer from the recovered rhamnolipid was added. Then $1.0 \mathrm{~mL}$ of distilled water and $3.0 \mathrm{~mL}$ of the $0.2 \%$ anthrone in $75 \%$ sulfuric acid solution were also added in each. The test tubes were heated for 10 minutes in a water bath of boiling water. Extracts that were positive for glycolipids produced a dark green color in the anthrone solution.

\section{Thin Layered Chromatography}

Ethyl acetate layers of the strains which yielded a positive result in anthrone test were separated by spotting at a point of origin near the bottom of the pre-coated plate (silica gel 60, Sigma, USA). Then plates were developed in solvent system of chloroform: methanol: acetic acid $(65: 10: 2, \mathrm{v} / \mathrm{v} / \mathrm{v})$.

\section{Extraction and Partial Purification of Crude Rhamnolipid}

Bacterial isolates that showed positive results in anthrone test and TLC were purified for its precipitated rhamnolipids by extracting three times with ethyl acetate at room temperature. The solvent in the organic layer was removed using rotary evaporator leaving behind relatively pure rhamnolipids having an oil-like appearance (Zhang \& Miller, 1992; Gunther et al., 2005).

\section{Determination of Minimum Inhibitory Concentration (MIC) of Crude Extract on Solid Medium}

MIC was performed using Muller Hinton Agar. Five millimeter - diameter holes were bore on the $3 \mathrm{~mm}$-thick solid medium. A standard two-fold serial rhamnolipid dilution technique was applied to measure antibacterial activity (Washington \& Wood, 1995). Then $10 \mathrm{mg} / \mathrm{ml}$ stock solution of crude extract was diluted twofold to final concentrations: 100, 200, 400 and $800 \mu \mathrm{g} / \mathrm{mL}$ modified from Lotfabad, Shahcheraghi, and Shooraj (2013). Following the standard AST, a standardized inoculum of the organism was swabbed onto the surface of a Muller-Hinton agar plate, then $30 \mu \mathrm{L}$ of crude extract concentrations: $100,200,400$ and $800 \mu \mathrm{g} / \mathrm{mL}$ were pipetted and added to the $5 \mathrm{~mm}$ diameter holes. After plates were incubated for 24 hours at $37^{\circ} \mathrm{C}$, the diameter of zone inhibition (ZI) of the different test bacteria around each hole was measured and MIC was determined.

Two antibiotics, $5.0 \mu \mathrm{g} / \mathrm{mL}$ of Ciprofloxacin and $300 \mu \mathrm{g} / \mathrm{mL}$ of Nitrofurantoin were used as positive controls and ethyl acetate as negative control respectively. The diameters of inhibition zone of the crude extract and the known drugs were compared.

\section{Antioxidant Activity by DPPH Radical Scavenging}

This was done by preparing $5,10,15,20,25$ and $30 \mu \mathrm{g} / \mathrm{mL}$ concentrations of the rhamnolipid extracts in methanol. Similar concentrations of ascorbic acid were used as the standard antioxidant. $0.1 \mathrm{mM}$ solution of DPPH in methanol was prepared and $1 \mathrm{~mL}$ of this solution was added to $3 \mathrm{~mL}$ of the extracts and to ascorbic acid in their corresponding concentrations, handling of DPPH was done in the dark. The solutions were shaken vigorously and allowed to stand for 30 minutes in complete darkness to complete the reaction.

Absorbance of the solutions were measured at $517 \mathrm{~nm}$ by using UV-Vis spectrophotometry. DPPH scavenging effect (\%) or Percent inhibition was solved through the equation described by Shekhar and Anju (2014): Percent inhibition $=\mathrm{A}_{0}-\mathrm{A}_{1} / \mathrm{A}_{0} \times 100$. Control reaction was the absorbance of the DPPH solution in methanol without any extract added. $\mathrm{IC}_{50}$, the concentration at which $50 \%$ of the free radicals are oxidized, was determined through making inhibition curves in MS Excel.

\section{Statistical Analysis of Data}

For statistical analysis, Microsoft Excel 2013 and Minitab17 (Pennsylvania, USA) were used. Regression analysis was done in Microsoft Excel 2013 to determine the relationship of the zones of inhibition and concentrations of the extracts. The equations of the regression graphs for the extract against corresponding test bacteria were used to solve for the desired concentration that was needed for it to have a similar effect to that of the positive controls (Ciprofloxacin and Nitrofurantoin). The standard zone of inhibition for bacterial susceptibility to Ciprofloxacin is $21 \mathrm{~mm}$ (Ali $\boldsymbol{e t}$ al., 2010) while Nitrofurantoin is $17 \mathrm{~mm}$ (RxList, 2016). Kruskall-Wallis one-way analysis of variance was done in Minitab17. This was used to determine which extract was the most effective at inhibiting the test bacteria and this was also made in comparison with the control Nitrofurantoin but not Ciprofloxacin. Extracts were not anymore compared with Ciprofloxacin because it was already evident that there really was a difference with this control and the extracts in inhibiting bacteria.

\section{RESULTS AND DISCUSSION}

\section{Screening for Biosurfactant}

Biosurfactant screening results were summarized in Table 1. The biosurfactant screening results showed that strains 1,4 and 5 were positive (Table 1). The Parafilm M Test detects the presence of biosurfactants through the diameter of the drop when placed on parafilm. Biosurfactant would reduce the tension between polar water solution and nonpolar surface. Therefore more biosurfactants present in the drop, the larger the diameter of the drop. The diameter of the negative control was $5 \mathrm{~mm}$ and all of the strains exhibited a larger drop diameter than distilled water. Studies on biosurfactants showed that stability 
of the test droplet would depend upon the amount of surfactant present in the drop (Walter et al., 2010). Droplets without or less biosurfactants would have hydrophilic molecules that would repel from the nonpolar surface. For the oil spread assay, positive biosurfactant production was observed of having a larger clear zone in comparison to the negative control. All strains except strain 2 were able to show a larger displacement of oil around its crude extract which signifies that these strains potentially had biosurfactants that can act as oil dispersants. Distortion of the grids in the microplate was observed in all strains which indicates for biosurfactant production. All strains were positive for this assay which indicated that these strains had enough biosurfactants to induce optical distortion.

The emulsification assay test of a biosurfactant is based on the formation of an emulsion layer that would decrease the surface tension between the water in the aqueous test solution and kerosene. None of the strains produced a biosurfactant that could form a stable emulsion layer after the standard 24 hours. The critical micelle concentration $(\mathrm{CMC}$ ) of rhamnolipid is $0.08 \%$ (Sekhon Randhawa \& Rahman, 2014), it is quite low compared to biosurfactants. The CMC of a biosurfactant signifies the least amount of the biosurfactant needed in order for it to form micelles and emulsify oil efficiently. The lower the CMC, the more efficient it is as an emulsifier. The result implied that the extracts did not produce enough biosurfactant for it to reach the CMC. The CTAB agar plate detects the production of anionic biosurfactants (Walter et al., 2010) secreted by the microorganism. All the strains yielded negative result for the CTAB agar plate wherein no blue halo was observed and this could be because of the minute amount of rhamnolipid present the Pseudomonas isolate extracts as explained that the size of the zone of precipitation is proportional to the amount of biosurfactant present in the sample (Rahman et al., 2010).

Table 1 Biosurfactant screening results of six Pseudomonas isolates

\begin{tabular}{cccccccc}
\hline Strain & $\begin{array}{c}\text { Parafilm } \\
\text { M test } \\
(\mathbf{m m})\end{array}$ & $\begin{array}{c}\text { Oil } \\
\text { spread } \\
(\mathbf{m m})\end{array}$ & $\begin{array}{c}\text { Microplate } \\
\text { assay }\end{array}$ & $\begin{array}{c}\text { Emulsification } \\
\text { Index (\%) }\end{array}$ & $\begin{array}{c}\text { CTAB } \\
\text { agar } \\
\text { plates }\end{array}$ & Anthrone & TLC \\
\hline 1 & 6 & 52 & + & 0 & - & + & + \\
2 & 6 & 6 & + & 0 & - & - & - \\
3 & 6.5 & 10 & + & 0 & - & - & - \\
4 & 7 & 34 & + & 0 & - & + & + \\
5 & 7 & 10 & + & 0 & - & + & + \\
6 & 7 & 9 & + & 0 & - & - & - \\
Control & 5 & 0 & - & 0 & - & - & - \\
\hline
\end{tabular}

It was evident that Pseudomonas reactans (strain 2) was negative in all the assays for biosurfactant screening except for the Parafilm M test and Microplate assay. This indicated that $P$. reactans has the least potential to produce rhamnolipids. The biosurfactant screening tests are not yet enough to conclude that these strains have rhamnolipids. It only indicated that these strains have produced biosurfactants. The anthrone test determined if the biosurfactants detected in the previous assays were glycolipids. Thin-Layered Chromatography would then verify if the glycolipid is a rhamnolipid. The crude extracts of strains 1,4 , and 5 were able to form a distinct dark green colored complex that indicates the presence of carbohydrate (Figure 1). This was most evident in strain 5. The anthrone test is based on the reaction of sugar with the anthrone reagent under acidic conditions to yield a green colored complex. The carbohydrates in strains 1,4 , and 5 were hydrolyzed by acid treatment to form furfurals and hydroxymethyl furfural. These furfural are then condensed by anthrone reagent to form a blue green colored complex. Strain 1 had the faintest green colored complex followed by strain 4 while strain 5 had the darkest colored complex by which it could be generated that strain 5 had the highest amount of carbohydrates present followed by strain 4 and strain 1 . These strains are determined to have reducing and non-reducing sugars because of the presence of the strongly oxidizing sulfuric acid.

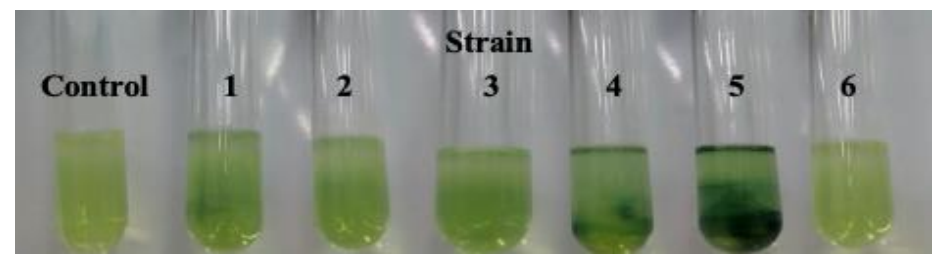

Figure 1 Anthrone test, negative control, and strains 1 - 6 (left to right)

Thin-layer chromatography (TLC) has been used extensively for determining the composition of culture broth extracts of rhamnolipids (de Koster et al., 1994; Rendell et al., 1990; Syldatk et al., 1985). The normal-phase chromatography on the silica 60 plates with the solvent mixture of chloroform-methanol-acetic acid (65:10:2) allowed for the division of the mono- and disaccharide polar head groups of the rhamnolipid. Though the staining and bands of the rhamnolipid standard were very dark and thick since it is highly concentrated, the crude extracts of strains 1,4 , and 5 were able to form light thin bands comparable to the standard (Figure 2). The organic solvent system was able to extract the lipid containing amphiphatic molecules present in strains 1,4 and 5. This indicated that these strains were positive for rhamnolipids. It was noted that strain 1 had a very faint band.

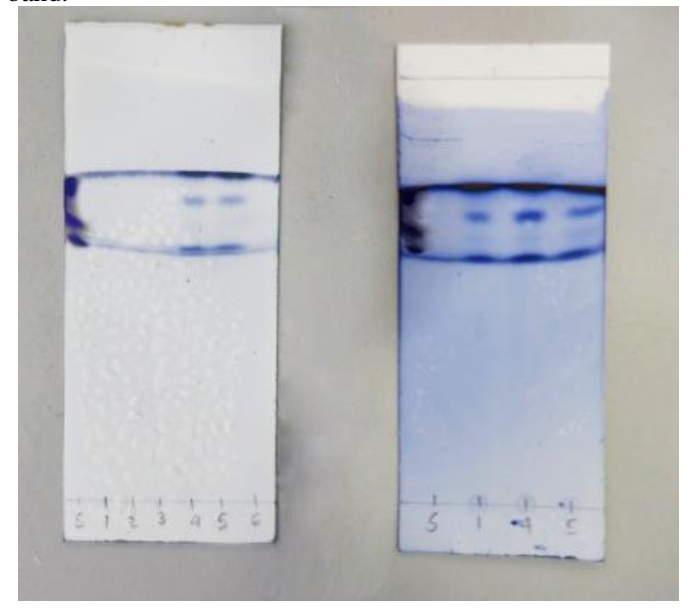

Figure 2 Only strains 1, 4, and 5 formed bands in the TLC test

The biosurfactant screening tests showed that only Pseudomonas poae (strain 1), Pseudomonas fluorescens (strain 4) and Pseudomonas libanensis (strain 5) were the only Pseudomonas species that could potentially produce rhamnolipids in the study. Studies that utilized terrestrial $P$. fluorescens and $P$. libanensis from oil polluted soils showed that these two species can really produce rhamnolipids. The environment where the Pseudomonas isolates used in the study was unlike those that are mostly experienced by Pseudomonas that are used in rhamnolipid studies. The underwater cave of Casili, Balamban was described by one of the Filipino Cave Divers to be free of oil pollution but was instead polluted by agricultural waste. Wastes coming from piggeries and farms near the area tended to seep into the waters of the cave. Other studies usually get their isolates from areas that encounter oil stress such as those that had an oil spill since exposure to hydrophobic pollutants in these environments become selective for biosurfactant producers. It is under this stressful condition that pseudomonads exhibit the greatest capacity to produce rhamnolipids (Arino et al., 1996). This explains why only 3 out of the 6 isolates were able to potentially produce rhamnolipids since the Pseudomonas isolated were not used to being in an oil polluted environment. The biosurfactant screening of the study imply that not all Pseudomonas species 
have the capacity to produce biosurfactants and that $P$. poae, $P$. fluorescens, and $P$. libanensis can be induced to produce biosurfactants. Though the Pseudomonas used in the study were isolated from non-oil polluted areas, it was determined that as long as they are stressed under the proper conditions, they can produce biosurfactants.

\section{Antibacterial Activity}

Only the rhamnolipid extracts of Pseudomonas poae (strain 1), Pseudomonas fluorescens (strain 4), and Pseudomonas libanensis (strain 5) were tested for their antibacterial activity. This was because these were the strains that exhibited the greatest potential in producing rhamnolipids during the biosurfactant screening process as discussed earlier. Table 2 shows the comparison of mean zones of inhibition results of the crude rhamnolipid extract produced by Strains 1, 4 and 5 at different concentrations against two Gram-negative bacteria (Escherichia coli,
Serratia marcescens) and two Gram-positive bacteria (Bacillus cereus and Staphylococcus aureus). All the strains exhibited their largest zone of inhibition at its highest concentration. Crude rhamnolipid extract produced by Strain 5 was observed to have its largest zone of inhibition, $10.89 \mathrm{~mm}$, against Escherichia coli. Crude rhamnolipid extract of Strain 1 follows Strain 5 with the zone of inhibition of $9.67 \mathrm{~mm}$ against Serratia marcescens and Escherichia coli. The produced crude rhamnolipid extract of Strain 4 ranked third among the three strains' largest zone of inhibition with $8.11 \mathrm{~mm}$ against Escherichia coli. The crude rhamnolipid extracts produced by all of the strains affected more the growth of Gram-negative bacteria than Gram-positive bacteria. The negative control, ethyl acetate, was not able to affect the growth of any test organism while the positive controls, Ciprofloxacin and Nitrofurantoin inhibited the growth of all test organisms with Ciprofloxacin stronger than Nitrofurantoin and all other crude rhamnolipid extracts (Table 2).

Table 2 Mean zones of inhibition of crude rhamnolipid extracts of the 3 Pseudomonas strains at different concentrations versus commercial antibiotics (Nitrofurantoin and Ciprofloxacin).

\begin{tabular}{|c|c|c|c|c|c|c|c|c|c|c|c|c|c|c|c|}
\hline \multirow{3}{*}{ Microorganisms } & \multicolumn{4}{|c|}{ Strain 1} & \multicolumn{4}{|c|}{ Strain 4} & \multicolumn{4}{|c|}{ Strain 5} & \multirow[t]{2}{*}{ Nitrofurantoin } & \multirow[t]{2}{*}{ Ciprofloxacin } & \multirow[t]{2}{*}{ Ethyl acetate } \\
\hline & \multicolumn{12}{|c|}{ Extract Concentration $(\mu \mathrm{g} / \mathrm{mL})$} & & & \\
\hline & 100 & 200 & 400 & 800 & 100 & 200 & 400 & 800 & 100 & 200 & 400 & 800 & 300 & 5 & $100 \%$ \\
\hline S. marcescens & 5.11 & 6.11 & 8.44 & 9.67 & 6.22 & 5.67 & 6.00 & 8.00 & 5.50 & 6.00 & 7.22 & 9.44 & 5.11 & 36.67 & 5.00 \\
\hline E. coli & 5.44 & 6.44 & 8.56 & 9.67 & 5.44 & 5.33 & 6.78 & 8.11 & 5.89 & 6.94 & 9.00 & 10.89 & 9.78 & 32.11 & 5.00 \\
\hline B. cereus & 5.00 & 6.22 & 7.13 & 8.56 & 5.00 & 5.11 & 5.22 & 5.67 & 5.00 & 5.67 & 6.33 & 9.67 & 8.67 & 29.89 & 5.00 \\
\hline S. aureus & 5.22 & 5.56 & 7.33 & 7.67 & 5.33 & 5.56 & 6.22 & 6.22 & 5.78 & 6.78 & 7.74 & 9.56 & 7.67 & 27.22 & 5.00 \\
\hline
\end{tabular}

Note: Zones of inhibition were measured in millimetres (mm)

As observed, all of the rhamnolipid extracts of the 3 strains were able to inhibit the test bacteria to some degree with extracts coming from Pseudomonas fluorescens (strain 4) inhibiting the least. All of the extracts show a positive correlation between its concentration and the zone of inhibition against test organisms (Table 3) and the positive correlation between the concentration and the zone of inhibition has a statistical significance with the $P$ value of 0.024214 which render the $r^{2}$ values reliable. This implies that if the extracts were found at higher concentrations, the greater zone of inhibitions would have been observed. Nonetheless, this also proves that the rhamnolipids in the crude extract did have antibacterial properties against the 4 test organisms.

Table $3 \mathrm{R}^{2}$ values for zone of inhibition and extract concentrations in regression analysis

\begin{tabular}{cccc}
\hline Test Microorganism & Strain 1 & Strain 4 & Strain 5 \\
\hline S. marcescens & 0.9025 & 0.7638 & 0.9995 \\
E. coli & 0.899 & 0.9557 & 0.958 \\
B. cereus & 0.9405 & 0.9858 & 0.9742 \\
S. aureus & 0.8131 & 0.7204 & 0.9805 \\
\hline
\end{tabular}

p-value $=0.024214$

The strain with least MIC was Strain 5 while Strain 2 consistently had 200 as MIC throughout (Table 4). A possible reason for the different responses of the test bacteria towards rhamnolipid extracts coming from the 3 strains could be that the rhamnolipids produced by each strain were different in chemistry. There are several types of rhamnolipids and the type produced is dependent upon the bacterial strain, carbon source used and process strategy (Lotfabad, Shahcheraghi, and Shooraj, 2013). Characterization of the rhamnolipid extracts from each strain would be needed to determine the specific type of rhamnolipid produced.

Table 4 Minimum inhibitory concentration (MIC) of crude rhamnolipid extracts from the 3 Pseudomonas strains against test bacteria.

\begin{tabular}{cccc}
\hline \multirow{2}{*}{ Test Organism } & \multicolumn{3}{c}{ MIC $(\boldsymbol{\mu g} / \mathbf{m L})$} \\
\cline { 2 - 4 } & Strain 1 & Strain 4 & Strain 5 \\
\hline S. marcescens & 200 & 100 & 100 \\
E. coli & 200 & 400 & 100 \\
B. cereus & 200 & 800 & 200 \\
S. aureus & 200 & 200 & 100 \\
\hline
\end{tabular}

Kruskall-Wallis test was done to determine which strain produced the most lethal extract against the test bacteria. It also elucidated whether the extracts had significantly different effects in inhibiting the test bacteria. A p-value of $\mathrm{P}=0.000$ (Table 5), indicating that there is a significant difference among the extracts when it came to inhibiting the test bacteria. Extracts coming from strain 1 were most effective against Serratia marcescens and Staphylococcus aureus while those from strain 5 were the most effective against Escherichia coli and Bacillus cereus (Table 5). The rhamnolipid extracts were better at inhibiting the test bacteria compared to the positive control, Nitrofurantoin (Table 5).

Table 5 Strain effectivity ranking through Kruskal-Wallis Test.

\begin{tabular}{cc}
\hline Treatment & Average Rank \\
\hline 6 & 110.2 \\
10 & 99.8 \\
1 & 96.4 \\
9 & 93.1 \\
12 & 90.4 \\
4 & 90.1 \\
14 & 89.6 \\
3 & 82.4 \\
7 & 80.6 \\
5 & 67.1 \\
15 & 66.4 \\
2 & 55.5 \\
16 & 55.3 \\
11 & 37.1 \\
8 & 27.9 \\
13 & 18.2 \\
& $\mathbf{P}=0.000$ \\
\hline
\end{tabular}

LEGEND: Codes for treatment in Kruskal-Wallis Test

$1=\mathrm{S} 1$ at $800 \mathrm{\mu g} / \mathrm{mL}$ against Serratia marcescens

$2=\mathrm{S} 4$ at $800 \mu \mathrm{g} / \mathrm{mL}$ against Serratia marcescens

$3=\mathrm{S} 5$ at $800 \mu \mathrm{g} / \mathrm{mL}$ against Serratia marcescens

$4=\mathrm{S} 1$ at $800 \mu \mathrm{g} / \mathrm{mL}$ against Escherichia coli

$5=\mathrm{S} 4$ at $800 \mu \mathrm{g} / \mathrm{mL}$ against Escherichia coli

$6=\mathrm{S} 5$ at $800 \mu \mathrm{g} / \mathrm{mL}$ against Escherichia coli

$7=\mathrm{S} 1$ at $800 \mu \mathrm{g} / \mathrm{mL}$ against Bacillus cereus

$8=\$ 4$ at $800 \mu \mathrm{g} / \mathrm{mL}$ against Bacillus cereus

$9=\mathrm{S} 5$ at $800 \mu \mathrm{g} / \mathrm{mL}$ against Bacillus cereus

$10=\mathrm{S} 1$ at $800 \mu \mathrm{g} / \mathrm{mL}$ against Staphylococcus aureus

$11=\$ 4$ at $800 \mu \mathrm{g} / \mathrm{mL}$ against Staphylococcus aureus

$12=\mathrm{S} 5$ at $800 \mu \mathrm{g} / \mathrm{mL}$ against Staphylococcus aureus

$13=$ Nitrofurantoin against Serratia marcescens

$14=$ Nitrofurantoin against Escherichia coli

$15=$ Nitrofurantoin against Bacillus cereus

$16=$ Nitrofurantoin against Staphylococcus aureus 
Rhamnolipids are reported to have strong antibacterial properties against grampositive bacteria (Lotfabad, Shahcheraghi, and Shooraj, 2013) and a few gram-negative bacteria (Kahlon, 2016). The crude rhamnolipid extracts produced by all of the strains affected more the growth of Gram-negative bacteria than Gram-positive bacteria and this is in contrast to the findings of Lotfabad et al., (2013) and Sotirova et al., (2008) which showed that biosurfactants were active against Gram-positive bacteria and its presence does not affect the growth of Gram-negative strains. The rhamnolipid in the experiment could have altered the permeability of the Gram negative cell membrane and this new information could be used for the formulation of antibiotic and reinforcement, highlighting rhamnolipid potential in biomedicine. Pseudomonas libanensis (strain 5) was observed to have the greatest antibacterial activity among the 3 strains extracted. Previous studies done on extract coming from other strains of Pseudomonas libanensis also reported similar results of its good antimicrobial activity. This antimicrobial activity of Pseudomonas libanensis could be attributed to its ability to produce a cyclic lipopeptide, viscosin (Kahlon, 2016) in addition to its ability to produce rhamnolipids.

\section{Antioxidant Activity by DPPH Radical Scavenging}

Antioxidant activity in rhamnolipids has not been fully investigated in published papers. One fast and relatively cheaper way to determine the antioxidant activity of a compound is through the DPPH radical scavenging method. This method utilizes the Absorbance of a DPPH and extracts solution at $517 \mathrm{~nm}$ after it undergoes reaction. The mean Absorbance of the reference standard, ascorbic acid, and the crude rhamnolipid extracts coming from $P$. poae (strain 1), $P$. fluorescens (strain 4), and P. libanensis (strain 5) at various concentrations are found in Table 6 below. It was seen that there a decreasing trend of absorbance as the concentration of the extracts and the ascorbic acid increases, this is most pronounced in ascorbic acid.

Table 6 Absorbance of ascorbic acid and crude rhamnolipid extracts at various concentrations measured at $517 \mathrm{~nm}$.

\begin{tabular}{ccccc}
\hline $\begin{array}{c}\text { Concentration } \\
(\boldsymbol{\mu g} / \mathbf{m L})\end{array}$ & $\begin{array}{c}\text { Ascorbic } \\
\text { Acid (Abs) }\end{array}$ & $\begin{array}{c}\text { Strain 1 } \\
\text { Crude RL } \\
(\mathbf{A b s})\end{array}$ & $\begin{array}{c}\text { Strain 4 } \\
\text { Crude RL } \\
(\mathbf{A b s})\end{array}$ & $\begin{array}{c}\text { Strain 5 } \\
\text { Crude RL } \\
(\mathbf{A b s})\end{array}$ \\
\hline 5 & 0.191 & 0.196 & 0.221 & 0.166 \\
10 & 0.145 & 0.183 & 0.228 & 0.156 \\
15 & 0.125 & 0.180 & 0.160 & 0.156 \\
20 & 0.092 & 0.165 & 0.145 & 0.151 \\
25 & 0.042 & 0.154 & 0.157 & 0.146 \\
30 & 0.033 & 0.084 & 0.122 & 0.144 \\
\hline
\end{tabular}

It was observed that ascorbic acid has the greatest \% inhibition, followed by the crude rhamnolipid extracts of Strain 1 and Strain 4 while Strain 5 had the least \% inhibition. The \% inhibition of the extracts or standard when graphed against the concentrations through MS Excel, allows one to determine the equation of the line which allows the $\mathrm{IC}_{50}$ to be solved. The graphs are presented in Figure 3. The $\mathrm{R}^{2}$, regression equation, and $\mathrm{IC}_{50}$ of the extracts are in Table 7 .

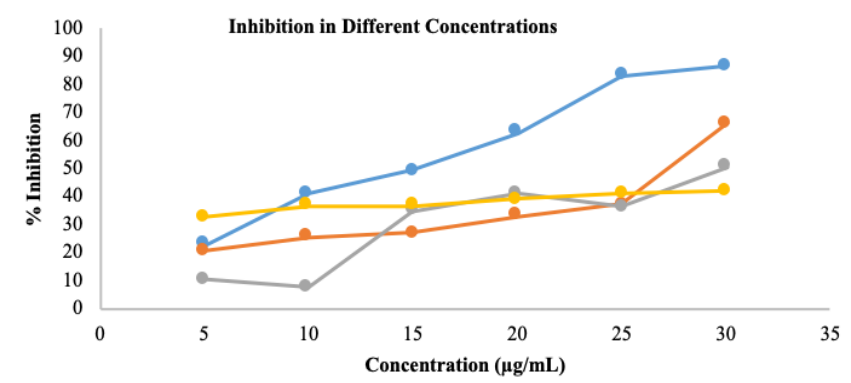

$\longrightarrow$ Ascorbic Acid $\longrightarrow$ Strain 1 crude RL $\longrightarrow$ Strain 4 crude RL $\longrightarrow$ Strain 5 crude RL

Figure 3 Percent Inhibition of ascorbic acid and crude RL extracts at various concentrations.
It was seen that ascorbic acid had the greatest antioxidant activity compared to the crude rhamnolipid extracts (Figure 3). It was also observed that at the lowest concentration, crude rhamnolipid extracts from strain 5 had the greatest $\%$ inhibition of the free radical but at the highest concentration, it was the least (Figure 3). Ascorbic acid had the least $\mathrm{IC}_{50}$ which further proves its great antioxidant activity since even at a low concentration, it can already reduce $50 \%$ of the free radicals. This is seen on Table 7 below. Among the crude rhamnolipid extracts, those coming from strain $1(P$. poae) exhibited the greatest antioxidant activity though its difference with strain 4 (P. fluorescens) is not that far off. Extracts from strain 5 (P. libanensis) relatively had the least antioxidant activity.

Table $7 \mathrm{R}^{2}$ value, regression equation, inhibitory concentration $\left(\mathrm{IC}_{50}\right)$ of ascorbic acid and crude rhamnolipid extracts.

\begin{tabular}{ccccc}
\hline $\begin{array}{c}\text { Solution } \\
\text { Tested }\end{array}$ & $\mathbf{R}^{2}$ & Linear equation & IC $_{\mathbf{5 0}}$ & $\begin{array}{c}\text { P- } \\
\text { value* }\end{array}$ \\
\hline Ascorbic Acid & 0.9776 & $\mathrm{y}=2.6115 \mathrm{x}+12.002$ & 14.5502 & 0.000 \\
S1 crude RL & 0.7756 & $\mathrm{y}=1.5315 \mathrm{x}+8.2411$ & 27.2667 & 0.021 \\
S4 crude RL & 0.8191 & $\mathrm{y}=1.6757 \mathrm{x}+0.9717$ & 29.2584 & 0.013 \\
S5 crude RL & 0.9478 & $\mathrm{y}=0.3412 \mathrm{x}+32.074$ & 52.5381 & 0.001 \\
\hline Note: calculated using Pearson correlation
\end{tabular}

The results clearly showed that ascorbic acid had the greatest antioxidant activity which was expected since ascorbic acid is one of the known standard antioxidants with an $\mathrm{IC}_{50}$ of $14.5502 \mu \mathrm{g} / \mathrm{mL}$ in the study. It was observed that all of the crude rhamnolipid extracts had antioxidant activity but it was not as great as that of ascorbic acid. The $\mathrm{IC}_{50}$ of crude rhamnolipid extracts from $P$. poae (Strain 1) was $27.2667 \mu \mathrm{g} / \mathrm{mL}$, P. fluorescens (Strain 4) had 29.2584 while P. libanensis (Strain 5) had the greatest $\mathrm{IC}_{50}$ which was 52.5381. This indicated that the strains had antioxidant activity and that crude rhamnolipid extracts from $P$. poae had the greatest radical scavenging activity among the crude rhamnolipid extracts investigated in the study.

Ascorbic acid as an antioxidant deters oxidation of free radicals by donating an electron to the radical in order for the radical to be stable (Nimse \& Palb, 2015). The $\mathrm{R}^{2}$ value of ascorbic acid and the crude rhamnolipid extracts had strong correlations since they ranged from $0.8191-0.9478$ (Table 7). The average $\mathrm{R}^{2}$ value of the crude rhamnolipid extracts was 0.88 , a strong correlation. Strong positive correlation indicates that it is truly the extracts themselves that acted as the antioxidant ( $\mathbf{L i}, \mathbf{W u}, \boldsymbol{\&}$ Huang, 2009). This shows that the crude rhamnolipid extracts used in the study exhibited antioxidant activity and that increasing concentrations of the extracts would also result in greater free radical scavenging activity since the correlation is positive. No study describing the mechanism of how a biosurfactant can act as an antioxidant has been published so far. Though there are already studies that claim that some glycolipids such as sophorolipids and MELs do show antioxidant activity (Kosaric \& Sukan, 2015). This only shows that more research regarding the bioactivity of biosurfactants like rhamnolipids is needed to further determine and verify the possible application of these compounds in various industries.

\section{CONCLUSION}

The study has shown that not all of the isolated Pseudomonas strains from the freshwater sediment can produce rhamnolipids. The rhamnolipids produced from Pseudomonas poae, Pseudomonas fluorescens, and Pseudomonas libanensis exhibited antibacterial activity against Gram-positive and Gram-negative used in the study. Crude rhamnolipids at a higher concentration had larger zones of inhibition especially against Escherichia coli, Staphylococcus aureus, and Bacillus cereus. The rhamnolipid extracts from $P$. poae and $P$. libanensis are comparable to commercial antibiotic Nitrofurantoin against all the test microorganisms (Serratia marcescens, Escherichia coli, Staphylococcus aureus, and Bacillus cereus) but not to Ciprofloxacin. Through DPPH radical scavenging method, it was determined that all of the crude rhamnolipid extracts showed antioxidant activity but not comparable to that of the standard antioxidant, ascorbic acid.

Acknowledgments: This study was supported by Filipino Cave Divers, Dr. Antonio E. Batomalaque, Dr. Julie B. Otadoy, Annie Diola, MSc and under the 
funded DOST MECO-TECO glycolipid research project headed by Dr. Paul John L. Geraldino.

\section{REFERENCES}

Ali, S., Zehra, A., Naqvi, B., Shah, S., \& Bushra, R. (2010). Resistance Pattern of Ciprofloxacin Against Different Pathogens. Oman Medical Journal, 25 (4), 294298. https://dx.doi.org/10.5001/omj.2010.85

Arino, S., Marchal, R. \& Vandecasteele, J.P. (1996). Identification and production of a rhamnolipidic biosurfactant by a Pseudomonas species. Appl Microbiol Biotechnol., 45, 162. https://doi.org/10.1007/s002530050665

Bauman, R. (2006). Understanding Microbiology: An Introduction. Benjamin Cummings, San Francisco, pp. 335.

Bhatnagar, I., Kim, S.K. (2010). Immense Essence of Excellence: Marine Microbial Bioactive Compounds. Mar. Drugs, 8(10), 2673-2701. http://dx.doi.org/10.3390/md8102673

Cardozo, V. F., Oliveira, A.G., Nishio, E.K., Perugini, M.R., Andrade, C.G., Silveira, W.D., Nakazato, G. (2013). Antibacterial activity of extracellular compounds produced by a Pseudomonas strain against methicillin-resistant Staphylococcus aureus (MRSA) Strains.. Ann Clin Microbiol Antimicrob., 12, 12. https://dx.doi.org/10.1186/1476-0711-12-12

de Jesus Cortes-Sanchez, A., Hernandez-Sanchez, H., Jaramillo-Flores, M.E. (2013). Biological activity of glycolipids produced by microorganisms: New trends and possible therapeutic alternatives. Microbiological Research, 168 (1), 22-32. https://dx.doi.org/10.1016/j.micres.2012.07.002

de Koster, C.G., Vos, B., Versluis, C., Heerma, W., \& Haverkamp, J. (1994). High-performance thin-layer chromatography/fast atom bombardment (tandem) mass spectrometry of Pseudomonas rhamnolipids. Biol. Mass Spectrom., 23 (4), 179-85. https://dx.doi.org/10.1002/bms.1200230402

Gunther, N. W., Nunez, A., Fett, W., Solaiman, D.K.Y. (2005). Production of Rhamnolipids by Pseudomonas chlororaphis, a Nonpathogenic Bacterium. Applied and Environmental Microbiology, $71 \quad$ (5), 2288 2293.https://dx.doi.org/10.1128/AEM.71.5.2288-2293.2005

Haba, E., Pinazo, A., Jauregui, O., Espuny, M.J., Infante, M.R., Manresa, A. (2003). Physicochemical characterization and antimicrobial properties of rhamnolipids produced by Pseudomonas aeruginosa 47T2 NCBIM 40044. Biotechnol. Bioeng., 81, 316-22. https://dx.doi.org/10.1002/bit.10474

Isnansetyo, A., Kamei, Y. (2009). Bioactive substances produced by marine isolates of Pseudomonas. J. Ind. Microbiol. Biotechnol., 36, 1239. https://dx.doi.org/10.1007/s10295-009-0611-2

Kahlon, R. (2016). Pseudomonas: Molecular and Applied Biology. Springer International Publishing Switzerland. https://dx.doi.org/10.1007/978-3-319$\underline{31198-2}$

Kosaric, N., \& Sukan, F. (2015). Biosurfactants production and utilization Processes, Technologies, and Economics (Vol. 159). New York: Taylor \& Francis Group.

Li, X., Wu, X., \& Huang, L. (2009). Correlation between Antioxidant Activities and Phenolic Contents of Radix Angelicae Sinensis (Danggui). Molecules, 14, 5349-5361. https://dx.doi.org/10.3390/molecules14125349

Lotfabad, T., Shahcheraghi, F., \& Shooraj, F. (2013). Assessment of Antibacterial Capability of Rhamnolipids Produced by Two Indigenous Pseudomonas aeruginosa Strains. Jundishapur Journal of Microbiology, 6 (1), 29-35. https://dx.doi.org/10.5812/jjm.2662

Molles, M. (2010). Ecology Concepts and Application. New York: McGraw-Hill Education.

Nimse, S.B., \& Pal, D. (2015). Free radicals, natural antioxidants, and their reaction mechanisms. Royal Society of Chemistry, 5, 27986-28006.

https://dx.doi.org/10.1039/C4RA13315C

Rahman, P.K., Pasirayi, G., Auger, V. \& Ali, Z. (2010). Production of rhamnolipid biosurfactants by Pseudomonas aeruginosa DS10-129 in a microfluidic bioreactor. Biotechnol. Appl. Biochem., 55 (1), 45 - 52. https://dx.doi.org/10.1042/BA20090277

Rendell, N.B., Taylor, G.W., Somerville, M., Todd, H., Wilson, R., \& Cole, P. J. (1990). Characterisation of Pseudomonas rhamnolipids. Biochim. Biophys Acta, 1045, 189-193. https://dx.doi.org/10.1016/0005-2760(90)90150-V

RxList. (2016). Clinical Pharmacology: http://www.rxlist.com/macrobid drug/clinical-pharmacology.htm
Sekhon Randhawa, K.K., \& Rahman, P.K.S.M. (2014). Rhamnolipid biosurfactants - past, present, and future scenario of global market. Front. Microbiol., 5, 454. https://dx.doi.org/10.3389/fmicb.2014.00454

Singh, P., Cameotra, S.S. (2004). Potential applications of microbial surfactants in biomedical sciences. Trends Biotechnol, 22, 142-146. https://dx.doi.org/10.1016/j.tibtech.2004.01.010

Sotirova, A.V., Spasova, D.I., Galabova, D.N., Karpenko, E., Shulga, A. (2008). Rhamnolipid-biosurfactant permeabilizing effects on gram-positive and gramnegative bacterial strains. Curr. Microbiol., 56, 639644. https://dx.doi.org/10.1007/s00284-008-9139-3

Syldatk, C., Lang, S., Matulovic, U., \& Wagner, F. (1985). Production of Four Interfacial Active Rhamnolipids from n-Alkanes or Glycerol by Resting Cells of Pseudomonas species DSM 2874. Zeitschrift für Naturforschung C, 40(1-2), 6167. https://dx.doi.org/10.1515/znc-1985-1-213

Thanomsub, B., Pumeechockchai, W., Limtrakul, A., Arunrattiyakorn, P., Petchleelaha, W., Nitoda, T., \& Kanzaki, H. (2007). Chemical structures and biological activities of rhamnolipids produced by Pseudomonas aeruginosa B189 isolated from milk factory waste. Biores. Technol, 98, 1149-1153. https://dx.doi.org/10.1016/j.biortech.2005.10.045

Walter, V., Syldatk, C., Hausmann, R. (2010). Screening Concepts for the Isolation of Biosurfactant Producing Microorganisms. In: Sen R. (eds) Biosurfactants. Advances in Experimental Medicine and Biology (Vol 672). Springer, New York, NY. https://dx.doi.org/10.1007/978-1-4419-5979-9_1

Wang, Q., Fang, X., Bai, B., Liang, X., Shuler, P. J., Goddard, W.A.III, Tang, Y. (2007). Engineering bacteria for production of rhamnolipid as an agent for enhanced oil recovery. Biotechnology and Bioengineering, 98, $842-853$. https://dx.doi.org/10.1002/bit.21462

Washington, J., Wood, G. (1995). Antimicrobial susceptibility tests: Dilution and disc diffusion methods. In: Murray P, editor. Manual of Clinical Microbiology. 1327-1331. Washington: ASM Press.

Wiedenhoft, H. (2017). The Effects of Oil Pollution on Aquatic Ecosystems. Sciencing: $\quad$ http://sciencing.com/effects-oil-pollution-aquatic-ecosystems$11390 . \mathrm{html}$

Zhang, Y., \& Miller, R. (1992). Enhanced octadecane dispersion and biodegradation by a Pseudomonas rhamnolipid surfactant (biosurfactant). Appl. Environ. Microbiol., 58 (10), 3276-3282. 